\title{
Cognitive function in adolescence and the risk for premature diabetes and cardiovascular mortality in adulthood
}

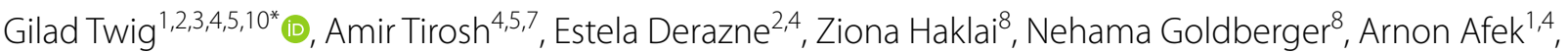 \\ Hertzel C. Gerstein ${ }^{6}$, Jeremy D. Kark ${ }^{9 \dagger}$ and Tali Cukierman-Yaffe ${ }^{4,5,11+}$
}

\begin{abstract}
Background: Epidemiological studies have demonstrated a relationship between cognitive function in youth and the future risk of death. Less is known regarding the relationship with diabetes related death. This study assessed the relationship between cognitive function in late adolescence and the risk for diabetes, cardiovascular- (CVD) and allcause mortality in adulthood.
\end{abstract}

Methods: This retrospective study linked data from 2,277,188 16-19 year olds who had general intelligence tests (GIT) conducted during pre-military recruitment assessment with cause of death as coded by the Israel Central Bureau of Statistics. The associations between cognitive function and cause-specific mortality were assessed using Cox models.

Results: There were 31,268 deaths that were recorded during 41,916,603 person-years of follow-up, with a median follow-up of 19.2 (IQR 10.7, 29.5) years. 3068, 1443, 514 and 457 deaths were attributed to CVD, CHD, stroke, and diabetes, respectively. Individuals in the lowest GIT vs. highest GIT quintiles in unadjusted models had the highest risk for all-cause mortality (HR 1.84, 95\% Cl 1.78, 1.91), total CVD (HR 3.32, 95\% Cl 2.93, 3.75), CHD (HR 3.49 95\% Cl 2.92, 4.18), stroke (HR 3.96 95\% Cl 2.85, 5.5) and diabetes-related (HR 6.96 95\% Cl 4.68, 10.36) mortality. These HRs were attenuated following adjustment for age, sex, birth year, body-mass index, residential socioeconomic status, education and country of origin for all-cause (HR 1.23, 95\% Cl 1.17, 1.28), CVD (HR 1.76, 95\% Cl 1.52, 2.04), CHD (HR 1.7 95\% Cl 1.37, 2.11), stroke (HR 2.03, 95\% Cl 1.39, 2.98) and diabetes-related (HR $3.1495 \% \mathrm{Cl} 2.00,4.94$ ) mortality. Results persisted in a sensitivity analyses limited to participants with unimpaired health at baseline and that accounted competing risk.

Conclusions: This analysis of over 2 million demonstrates a strong relationship between cognitive function at youth and the risk for diabetes, all-cause and CVD-related mortality independent of adolescent obesity.

Keywords: Adolescence, Cognitive performance, Diabetes, Mortality, Israelis

\section{Introduction}

Epidemiological studies have demonstrated a relationship between cognitive function in youth and the future risk of death [1-3]. Such studies have shown that intelligence quotient (IQ) measured in childhood is positively associated with age of death and cardiovascular death in

\footnotetext{
*Correspondence: Gilad.twig@gmail.com

† Jeremy D. Kark and Tali Cukierman-Yaffe contributed equally to this work

${ }^{10}$ Department of Military Medicine, Hebrew University, Jerusalem, Israel

Full list of author information is available at the end of the article
}

adulthood [4-7]. Childhood IQ has also been shown to be associated with chronic conditions such as hypertension and coronary heart disease [8-11]. In older adults, studies have reported a relationship between adult cognitive function and the risk of death [12], as well as with the incidence of cardiovascular disease (CVD) $[13,14]$ and diabetes [15]. Less is known regarding the relationship between cognitive function in adolescence (as measured by tools that discriminate between cognitively intact individuals) and the subsequent risk for diabetes-related death.

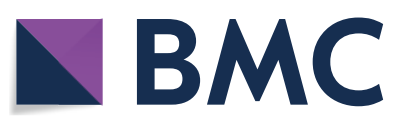

(c) The Author(s) 2018. This article is distributed under the terms of the Creative Commons Attribution 4.0 International License (http://creativecommons.org/licenses/by/4.0/), which permits unrestricted use, distribution, and reproduction in any medium, provided you give appropriate credit to the original author(s) and the source, provide a link to the Creative Commons license, and indicate if changes were made. The Creative Commons Public Domain Dedication waiver (http://creativecommons.org/ publicdomain/zero/1.0/) applies to the data made available in this article, unless otherwise stated. 
An unusual opportunity exists in Israel to assess the potential link between cognitive function in adolescence and risk for diabetes and cardiovascular-related mortality, as all eligible citizens are required by law to undergo a pre-military examination that includes both medical and psycho-social assessments. Thus extensive neuropsychological evaluation data and sociodemographic information is routinely collected in addition to a detailed medical examination. Linkage of this information with the Israel Central Bureau of Statistics officially coded cause of death database enables assessment of the relationship between cognitive function in late adolescence and the risk for diabetes and CVD-related death in adulthood.

\section{Materials and methods}

This historical prospective cohort study linked data from a large unselected population who had pre-military health examination during late adolescence with their underlying cause of death as routinely coded by the Israel Central Bureau of Statistics. The relationships between cognitive function and all-cause mortality, CVD mortality, and CHD-, stroke- and diabetes-related mortality were assessed.

\section{Study population}

One year prior to mandatory military service, at the age of $16-19$ years (mean age $17.3 \pm 0.4$ years), all eligible Israeli adolescents are required to undergo medical and psychosocial assessment. Arab citizens, Druze women and orthodox/ultraorthodox religious Jewish women are exempt from military service and largely do not undergo this compulsory assessment. Information regarding country of origin, education and residential socioeconomic status (SES) is collected in addition to an extensive neuropsychological/cognitive assessment. This analysis pertains to $2,277,188$ individuals who underwent prerecruitment evaluation between the years 1967 and 2010, irrespective of whether they served or not. Excluded from this analysis are 81,213 individuals for whom cognitive data or BMI was unavailable, 92,301 members of nonJewish minorities that were largely unrepresentative of their source populations and 3991 deaths that occurred from 1967 to 1980 for which the cause of death was not available. Of these, 3188 deaths were attributed to causes related to military service, and a simulation indicated that only 19 cardiovascular deaths were expected to be missed from analysis due to their young age $[16,17]$, thereby suggesting a negligible possible effect on the results.

\section{Evaluation of cognitive function at baseline}

The general intelligence test (GIT), conducted as part of the pre-military recruitment assessment, has been used extensively as an investigative tool, as previously described $[15,18,19]$. It includes evaluation of language ability and intellectual performance, and comprises four sub-tests: the Otis- $\mathrm{R}$ which is a measure of the ability to understand and carry out verbal instructions; Similarities- $\mathrm{R}$ which assesses verbal abstraction and categorization; Arithmetic- $\mathrm{R}$ which assesses mathematical reasoning, concentration and concept manipulation; and Raven's Progressive Matrices- $R$, which measures nonverbal abstract reasoning and visual-spatial problem solving abilities [20]. The sum of the scores of the 4 tests forms a validated measure of general intelligence (IQ) scored on a 9-point scale [21] that is adjusted from time to time. The GIT is administered by experienced personnel who undergo a 4-month training course.

\section{Mortality outcomes and documentation of cause of death} Study outcomes were deaths that had occurred by June 30, 2011, officially coded from death notifications by the Israel Central Bureau of Statistics according to the International Classification of Disease (ICD) 9 revision (1981-1997) and ICD-10 revision (1998-2011). The official cause of death was unavailable before the year 1981 . Deaths among Israel Defense Forces personnel have been computer-recorded since 1967 with a notation as to whether the death was service related. Outcomes analyzed were deaths attributed to all cardiovascular causes (ICD-9: 390-459; ICD-10: 100-99), to coronary heart disease (CHD) (ICD-9: 410-414; ICD-10: 120-125), stroke (ICD-9: 430-434, 436-438; ICD-10: 160-169) and diabetes (all types; ICD-9: 250; ICD-10: E08-13) as the underlying cause of death (see Fig. 1). Additionally, information regarding deaths from non-cardiovascular causes and all causes was also collected.

\section{Covariates}

Weight and height were measured at baseline by trained medics [22]. BMI was calculated as weight $(\mathrm{kg})$ divided by the squared height $\left(\mathrm{m}^{2}\right)$. A general physical examination was conducted by military physicians who also reviewed the participants' medical records and recorded standard diagnostic codes when relevant [23, 24]. Additional data regarding country of origin, education (divided into 4 categories: less than 9 years, 10 years, 11 years or 12 years) and residential SES were collected as detailed elsewhere $[15,25]$. Place of origin was defined as the birthplace of the father or grandfather (if the father was born in Israel) and categorized according to country of origin $[26,27]$.

\section{Statistical analysis}

Continuous variables were summarized using means and $\mathrm{SD}$, and counts with percentages were used for binary variables. The GIT score was converted into annual 

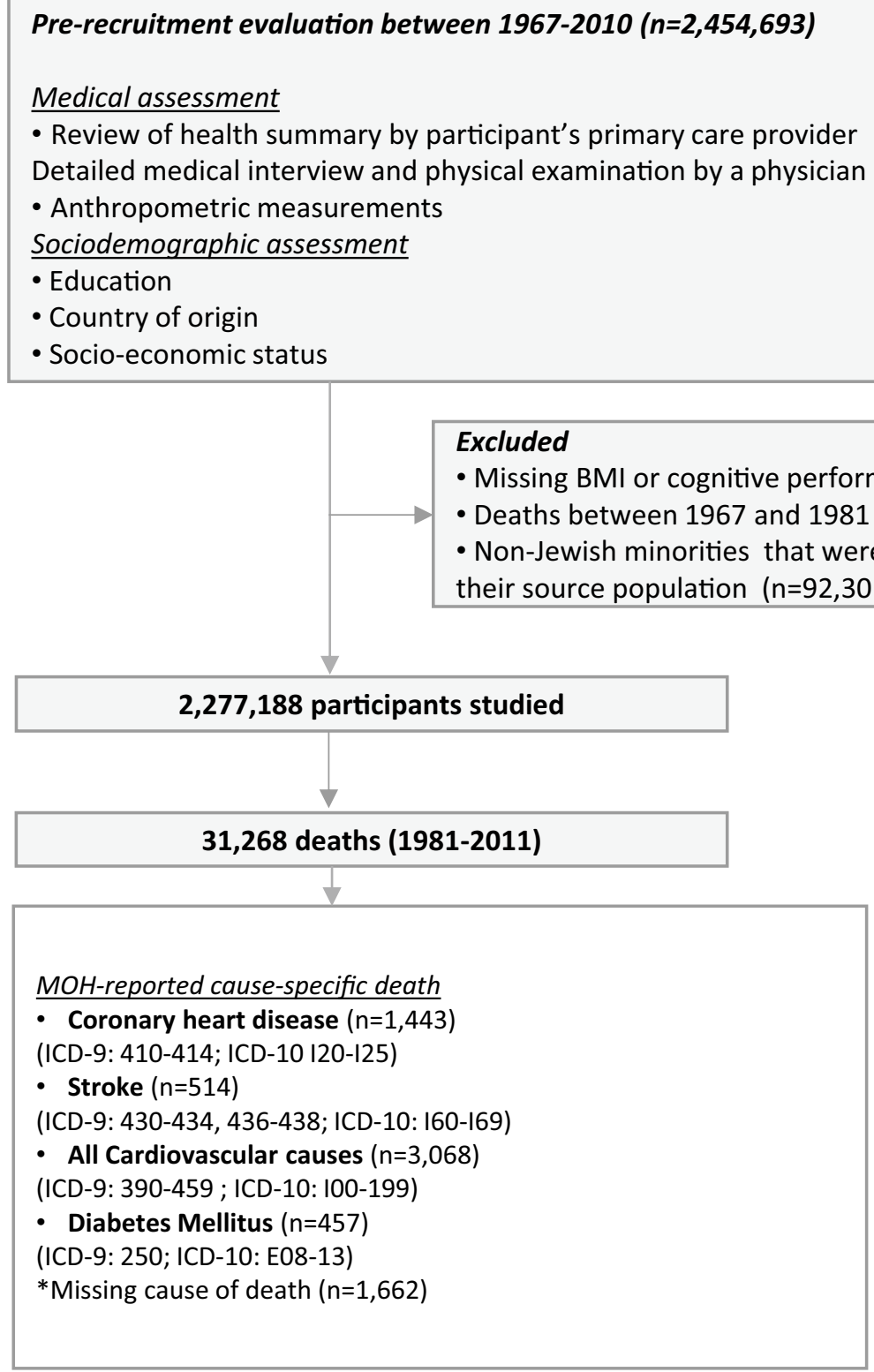

Fig. 1 Flow diagram of study sample

sex-specific z scores based on all those that underwent GIT assessment in each specific calendar year and was grouped into five groups using quintiles. The distribution of baseline variables across the 5 groups was computed. Cox proportional hazard models were used to estimate the hazard ratios (HR) and 95\% confidence intervals (CI) for time to first event for all cardiovascular mortality, for coronary heart disease (CHD), stroke, diabetes, non-cardiovascular-non-diabetes-related mortality and all-cause mortality comparing the highest quintile to the lower quintiles as well as for a unit change in the GIT z-score.
The unadjusted analyses were repeated after adjustment for age, birth year and sex (Model 1); these and BMI (Model 2); Model 2 variables and residential SES (Model 3 ); and Model 3 variables and education and country of origin (Model 4). The analysis were also repeated after (a) accounting for the competing risk of death from other causes [28] (b) including only those individuals who were classified at their pre-military assessment to be of unimpaired health (i.e. no indication of any medical diagnosis in the pre-recruitment medical evaluation that would limit combat service) to minimize residual 
confounding as reported previously [16, 17, 27, 29, 30]. Analyses were performed with SPSS statistical software, version 23.0.

\section{Results}

Between the years 1981 to 2011, 31,268 deaths were recorded during 41,916,603 person-years of follow-up, with a median follow-up of 19.2 (IQR 10.7, 29.5) years. Of these, 3068 deaths were attributed to all cardiovascular causes (CVD), 1443 to CHD, 514 to stroke, and 457 to diabetes (Fig. 1).

\section{Baseline characteristics}

Table 1 depicts the baseline characteristics of the cohort distributed according to quintiles of GIT. Individuals in the highest quintile compared to the lowest quintile were more likely to have completed high school education, to be designated as having unimpaired health, to be taller, and to be of European or former USSR origin but less likely to be of Asian or African origin. They were also more likely to reside in a higher SES locality, and less likely to be either overweight or underweight.

\section{GIT score and both all-cause and cause-specific mortality}

Table 2a shows the distribution of mortality and its person-years incidence by cause across GIT quintiles. As can be seen, individuals in the lowest GIT quintile had the highest total mortality with a graded decrease towards the higher GIS quintiles. CVD-, CHD-, stroke-, diabetesand non-CVD/non-diabetes-related mortality exhibited similar patterns.

\section{Multivariable-adjusted relationship between GIT score and both all-cause and cause-specific mortality}

The hazard ratios for total mortality and mortality due to cardiovascular disease, CHD, stroke and diabetes for the highest GIT quintile in comparison to other quintiles without adjustment and after adjustment for age, sex, birth year, BMI, SES, education and country of origin are presented in Fig. 2 and Table 2b. Overall, the lower the GIT the higher the hazard or all-cause and cause-specific mortality. As evident in Table 2b, individuals in the lowest GIT quintile vs. highest GIT quintile in the unadjusted models had the highest risk for all-cause mortality (HR 1.84, 95\% CI 1.78, 1.91), and total CVD (HR 3.32, 95\% CI 2.93, 3.75), CHD (HR 3.49 95\% CI 2.92, 4.18), stroke (HR 3.96 95\% CI 2.85, 5.5) and diabetes-related (HR 6.96 95\% CI 4.68, 10.36) mortality. These HRs were attenuated following adjustment for Model 4 variables for all-cause mortality (HR 1.23, 95\% CI 1.17, 1.28), total CVD (HR 1.76, 95\% CI 1.52, 2.04), CHD (HR 1.7 95\% CI 1.37, 2.11), stroke (HR 2.03, 95\% CI 1.39, 2.98) and diabetes-related (HR 3.14 95\% CI 2.00, 4.94) mortality, i.e. reduced by $72.6 \%, 67.2 \%, 71.9 \%, 65.2 \%$, and $64.1 \%$, respectively. Figure 3 depicts the relationship between a 1 unit lower GIT z-score on an interval scale and the risk for cause-specific mortality. As can be seen, serial adjustments for the various covariates attenuated the relationship modestly in Models 1, 2 and 3, but strongly in Model 4 which also adjusted for education, residential SES and origin, although the associations remained statistically significant. An additional analysis accounting for the competing risk of death from other causes yielded similar results (Additional file 1: Table S1). A sensitivity analysis that included only those individuals with unimpaired health at baseline $(\mathrm{N}=1,656,827)$ tended to attenuate the associations which, however, remained graded across quintiles of GIT and statistically significant (Additional file 1: Table S2).

\section{Discussion}

This analysis of 2,277,188 adolescents followed for a median of 19.2 years demonstrates an inverse association between cognitive scores at the age of $\sim 17$ years and the risk for all-cause death, cardiovascular mortality, and CHD, stroke and diabetes-related death. The strongest relationship observed was for the cognitive function and diabetes mortality. For example, there was a $\sim 1.8$-fold greater multivariable-adjusted hazard for total cardiovascular disease mortality in those who were in the lowest vs. the highest GIT score category, while for diabetesrelated death $\mathrm{a} \sim$ threefold greater hazard was observed. The associations, although substantially diminished after serial adjustments for variables that are known to be associated with both cognitive function and mortality (such as SES, education, origin and BMI), remained statistically significant.

This analysis is supported by data from previous studies conducted in children and in older individuals. An analysis of $\sim 31,000$ individuals with previous CVD reported a relationship between the Mini Mental State Examination Score (MMSE, a screening instrument for dementia) and incident cardiovascular events after adjustment for demographic and cardiovascular risk factors [14]. In an analysis of 11,140 individuals with type 2 diabetes who were followed for a median of 5 years there was also an inverse relationship between the MMSE score at baseline and incident CVD events that persisted after multivariate adjustment for sociodemographic variables [31]. In a study of 9204 individuals participating in the English Longitudinal study of Ageing, cognition was inversely associated with death from cancer, cardiovascular disease, respiratory illness and other causes [32]. These association were attenuated after adjustment for demographic and SES variables but remained significant. There have been several studies in young adults. An 
Table 1 Baseline characteristics of the study participants according to quintiles of general intelligence test scores

\begin{tabular}{|c|c|c|c|c|c|c|c|}
\hline & Q1 & Q2 & Q3 & Q4 & Q5 & Total & $\begin{array}{l}\text { p value } \\
\text { for linear } \\
\text { trend }\end{array}$ \\
\hline $\mathrm{N}$ of participants & 445,492 & 480,543 & 439,974 & 471,624 & 439,555 & $2,277,188$ & \\
\hline Female $\%$ & 31 & 43 & 44 & 44 & 40 & 40 & \\
\hline Age $\pm S D$ & $17.4 \pm 0.5$ & $17.3 \pm 0.4$ & $17.3 \pm 0.4$ & $17.3 \pm 0.4$ & $17.3 \pm 0.4$ & $17.3 \pm 0.4$ & 0.158 \\
\hline $\begin{array}{l}\mathrm{BMI} \pm \mathrm{SD}(\mathrm{kg} / \\
\left.\mathrm{m}^{2}\right)\end{array}$ & $21.7 \pm 3.6$ & $21.7 \pm 3.4$ & $21.7 \pm 3.3$ & $21.6 \pm 3.2$ & $21.6 \pm 3.1$ & $21.6 \pm 3.4$ & 0.071 \\
\hline Underweight \% & 8.7 & 6.9 & 6.0 & 5.7 & 5.4 & 6.5 & 0.024 \\
\hline Overweight \% & 8.9 & 8.8 & 8.6 & 8.4 & 7.8 & 8.5 & 0.016 \\
\hline Obese $\%$ & 4.9 & 4.0 & 3.5 & 3.3 & 3.0 & 3.7 & 0.011 \\
\hline $\begin{array}{l}\text { Height } \pm \text { SD } \\
\text { (males) }\end{array}$ & $171.8 \pm 6.8$ & $173.1 \pm 6.8$ & $173.6 \pm 6.7$ & $174.4 \pm 6.7$ & $175.1 \pm 6.7$ & $173.6 \pm 6.8$ & 0.001 \\
\hline $\begin{array}{l}\text { Height } \pm \text { SD } \\
\text { (females) }\end{array}$ & $160.9 \pm 6.2$ & $161.7 \pm 6.1$ & $162.0 \pm 6.1$ & $162.6 \pm 6.0$ & $163.1 \pm 6.0$ & $162.1 \pm 6.1$ & 0.001 \\
\hline $\begin{array}{l}\text { Completed high } \\
\text { school educa- } \\
\text { tion (\%) }\end{array}$ & 56.9 & 76.3 & 82.1 & 91.0 & 96.0 & 80.5 & $<0.001$ \\
\hline LOW SES \% & 33 & 26 & 23 & 20 & 19 & 24 & 0.001 \\
\hline $\begin{array}{l}\text { Unimpaired } \\
\text { health }\end{array}$ & 77.6 & 80.3 & 81.9 & 82.6 & 80.3 & 81.2 & 0.069 \\
\hline \multicolumn{8}{|c|}{ Country of origin (\%) } \\
\hline Israel & 4.6 & 5.0 & 5.7 & 6.4 & 7.6 & 5.8 & 0.003 \\
\hline USSR & 9.0 & 10.9 & 11.8 & 14.7 & 16.1 & 12.5 & 0.001 \\
\hline Asia & 30.6 & 29.5 & 26.6 & 21.9 & 16.0 & 25.0 & 0.007 \\
\hline Africa & 38.1 & 30.8 & 24.5 & 17.8 & 11.8 & 24.7 & $<0.001$ \\
\hline Europe & 13.7 & 22.6 & 30.9 & 39.0 & 48.4 & 30.8 & $<0.001$ \\
\hline Ethiopia & 4.0 & 1.3 & 0.5 & 0.2 & 0.1 & 1.2 & $0.057^{*}$ \\
\hline $\begin{array}{l}\text { Systolic/dias- } \\
\text { tolic BP } \pm S D \\
(\mathrm{mmHg})\end{array}$ & $\begin{array}{c}116.5 \pm 12.2 / \\
71.8 \pm 8.3\end{array}$ & $115.9 \pm 12.2 / 71.8 \pm 8.2$ & $116.3 \pm 12.3 / 71.6 \pm 8.2$ & $116.3 \pm 12.2 / 71.7 \pm 8.2$ & $117.1 \pm 12.3 / 71.7 \pm 8.2$ & $116.4 \pm 12.2 / 71.7 \pm 8.2$ & $0.110 / 0.319$ \\
\hline $\begin{array}{l}\text { Follow-up } \\
\qquad \begin{array}{l}\text { (mean } \pm S D) \\
\text { (years) }\end{array}\end{array}$ & $19.0 \pm 9.8$ & $19.2 \pm 8.9$ & $20.0 \pm 10.2$ & $19.0 \pm 9.7$ & $18.9 \pm 10.3$ & $19.2 \pm 9.8$ & 0.821 \\
\hline $\begin{array}{l}\text { Median follow- } \\
\text { up ( } 25 \text { th; } \\
\text { 75th) (years) }\end{array}$ & $18.8(10.3,28.7)$ & $18.9(13.2,27.0)$ & $19.7(10.6,32.0)$ & $18.9(11.0,29.3)$ & $19.9(9.3,30.1)$ & $19.2(10.7,29.5)$ & 0.759 \\
\hline $\begin{array}{l}\text { Cumulative } \\
\text { follow-up } \\
\text { (person-years) }\end{array}$ & $8,064,856$ & $8,840,363$ & $8,453,920$ & $8,577,783$ & $7,979,682$ & $41,916,603$ & 0.414 \\
\hline $\begin{array}{l}\text { Age at end of } \\
\text { follow-up } \\
( \pm S D)\end{array}$ & $37.0 \pm 12.1$ & $37.0 \pm 11.0$ & $38.4 \pm 12.7$ & $36.9 \pm 11.9$ & $36.9 \pm 12.5$ & $37.2 \pm 12.0$ & 0.907 \\
\hline
\end{tabular}

* Exponential trend $p<0.001$

inverse relationship between cognitive scores measured as part of military conscription in Denmark and risk for diabetes and for cardiovascular death was reported; the relationship was attenuated after adjustment for education but remained significant [12]. We have previously reported an inverse relationship between cognitive scores determined in adolescence and the subsequent risk of diabetes and dysglycemia $[15,33]$. The findings of our study strengthen the results of these studies and further suggest that sensitive measures of cognitive function can discriminate between younger individuals with a higher/ lower risk for diabetes and CVD related death.
There are several explanations for the relationship observed between cognitive function at age $\sim 17$ and the risk for diabetes and CVD-diabetes related death. First, as cognitive function is associated with education and SES, it may be that the relationship observed is a reflection of the already recognized relationship between these variables (and their possibly inadequate adjustment) and the subsequent risk for CVD death [34-38]. A limited number of socio-demographic variables were available for adjustment in our study; thus it may well be that unmeasured or insufficiently discriminating socio-demographic factors, especially in 
Table 2 The association between fifths of GIT scores and cause-specific mortality

\begin{tabular}{|c|c|c|c|c|c|c|}
\hline Mortality cause & Q1 & Q2 & Q3 & Q4 & Q5 & Total \\
\hline \multicolumn{7}{|c|}{ a. Cause-specific death according to GIT quintiles } \\
\hline All-cause, N (\%) & $\begin{array}{l}8765 \\
(1.97 \%)\end{array}$ & $\begin{array}{l}6306 \\
(1.31 \%)\end{array}$ & $\begin{array}{l}6188 \\
(1.41 \%)\end{array}$ & $\begin{array}{l}5221 \\
(1.11 \%)\end{array}$ & $\begin{array}{l}4788 \\
(1.09 \%)\end{array}$ & 31,268 \\
\hline Incidence (event/105 person-years) & 108.7 & 71.3 & 73.2 & 60.9 & 60.0 & 74.6 \\
\hline Total cardiovascular, N (\%) & $\begin{array}{l}1075 \\
(0.24 \%)\end{array}$ & $\begin{array}{l}641 \\
(0.13 \%)\end{array}$ & $\begin{array}{l}624 \\
(0.14 \%)\end{array}$ & $\begin{array}{l}394 \\
(0.08 \%)\end{array}$ & $\begin{array}{l}334 \\
(0.08 \%)\end{array}$ & 3068 \\
\hline Incidence (event/10 $0^{5}$ person-years) & 13.3 & 7.25 & 7.4 & 4.6 & 4.2 & 7.3 \\
\hline Coronary heart disease, $\mathrm{N}(\%)$ & $\begin{array}{l}526 \\
(0.12 \%)\end{array}$ & $\begin{array}{l}288 \\
(0.06 \%)\end{array}$ & $\begin{array}{l}308 \\
(0.07 \%)\end{array}$ & $\begin{array}{l}165 \\
(0.03 \%)\end{array}$ & $\begin{array}{l}156 \\
(0.04 \%)\end{array}$ & 1443 \\
\hline Incidence (event/10 $10^{5}$ person-years) & 6.5 & 3.3 & 3.6 & 1.9 & 1.9 & 3.4 \\
\hline Stroke, N (\%) & $\begin{array}{l}172 \\
(0.04 \%)\end{array}$ & $\begin{array}{l}115 \\
(0.02 \%)\end{array}$ & $\begin{array}{l}110 \\
(0.03 \%)\end{array}$ & $\begin{array}{l}72 \\
(0.02 \%)\end{array}$ & $\begin{array}{l}45 \\
(0.01 \%)\end{array}$ & 514 \\
\hline Incidence (event/10 $0^{5}$ person-years) & 2.1 & 1.3 & 1.3 & 0.8 & 0.6 & 1.2 \\
\hline Diabetes, N (\%) & $\begin{array}{l}184 \\
(0.04 \%)\end{array}$ & $\begin{array}{l}98 \\
(0.02 \%)\end{array}$ & $\begin{array}{l}96 \\
(0.02 \%)\end{array}$ & $\begin{array}{l}51 \\
(0.01 \%)\end{array}$ & $\begin{array}{l}28 \\
(0.01 \%)\end{array}$ & 457 \\
\hline Incidence (event/10 $0^{5}$ person-years) & 2.3 & 1.1 & 1.1 & 0.6 & 0.4 & 1.1 \\
\hline Non-CVD, non-diabetes, N (\%) & $\begin{array}{l}7506 \\
(1.68 \%)\end{array}$ & $\begin{array}{l}5567 \\
(1.16 \%)\end{array}$ & $\begin{array}{l}5468 \\
(1.24 \%)\end{array}$ & $\begin{array}{l}4776 \\
(1.01 \%)\end{array}$ & $\begin{array}{l}4426 \\
(1.01 \%)\end{array}$ & 27,743 \\
\hline Incidence (event/10 $0^{5}$ person-years) & 93.1 & 63.0 & 64.7 & 55.7 & 55.4 & 66.2 \\
\hline \multicolumn{7}{|l|}{ b. Cox proportional hazard models } \\
\hline $\begin{array}{l}\text { All cause } \\
\text { (unadjusted) }\end{array}$ & $\begin{array}{l}1.84 \\
(1.78,1.91)\end{array}$ & $\begin{array}{l}1.25 \\
(1.20,1.29)\end{array}$ & $\begin{array}{l}1.21 \\
(1.16,1.25)\end{array}$ & $\begin{array}{l}1.04 \\
(1.00,1.08)\end{array}$ & 1 & $4.10^{*} 10^{-231}$ \\
\hline $\begin{array}{l}\text { All cause } \\
\text { (adjusted) }\end{array}$ & $\begin{array}{l}1.23 \\
(1.17,1.28)\end{array}$ & $\begin{array}{l}1.08 \\
(1.04,1.13)\end{array}$ & $\begin{array}{l}1.04 \\
(1.00,1.08)\end{array}$ & $\begin{array}{l}1.01 \\
(0.98,1.06)\end{array}$ & 1 & $1.3^{*} 10^{-33}$ \\
\hline Total CVD (unadjusted) & $\begin{array}{l}3.32 \\
(2.93,3.75)\end{array}$ & $\begin{array}{l}1.92 \\
(1.68,2.19)\end{array}$ & $\begin{array}{l}1.71 \\
(1.49,1.95)\end{array}$ & $\begin{array}{l}1.15 \\
(0.99,1.33)\end{array}$ & 1 & $2.13^{*} 10^{-126}$ \\
\hline $\begin{array}{l}\text { Total CVD } \\
\text { (adjusted) }\end{array}$ & $\begin{array}{l}1.76 \\
(1.52,2.04)\end{array}$ & $\begin{array}{l}1.44 \\
(1.24,1.66)\end{array}$ & $\begin{array}{l}1.27 \\
(1.11,1.46)\end{array}$ & $\begin{array}{l}1.05 \\
(0.91,1.22)\end{array}$ & 1 & $1.3^{*} 10^{-14}$ \\
\hline $\begin{array}{l}\text { CHD } \\
\text { (unadjusted) }\end{array}$ & $\begin{array}{l}3.49 \\
(2.92,4.18)\end{array}$ & $\begin{array}{l}1.87 \\
(1.54,2.27)\end{array}$ & $\begin{array}{l}1.8 \\
(1.48,2.18)\end{array}$ & $\begin{array}{l}1.03 \\
(0.83,1.29)\end{array}$ & 1 & $1.21 * 10^{-66}$ \\
\hline $\begin{array}{l}\text { CHD } \\
\text { (adjusted) }\end{array}$ & $\begin{array}{l}1.70 \\
(1.37,2.11)\end{array}$ & $\begin{array}{l}1.36 \\
(1.09,1.68)\end{array}$ & $\begin{array}{l}1.31 \\
(1.07,1.60)\end{array}$ & $\begin{array}{l}0.95 \\
(0.76,1.18)\end{array}$ & 1 & $1.6^{*} 10^{-9}$ \\
\hline $\begin{array}{l}\text { Stroke } \\
\text { (unadjusted) }\end{array}$ & $\begin{array}{l}3.96 \\
(2.85,5.50)\end{array}$ & $\begin{array}{l}2.60 \\
(1.84,3.66)\end{array}$ & $\begin{array}{l}2.22 \\
(1.57,3.15)\end{array}$ & $\begin{array}{l}1.56 \\
(1.08,2.27)\end{array}$ & 1 & $5.06^{*} 10^{-24}$ \\
\hline $\begin{array}{l}\text { Stroke } \\
\text { (adjusted) }\end{array}$ & $\begin{array}{l}2.03 \\
(1.39,2.98)\end{array}$ & $\begin{array}{l}1.83 \\
(1.26,2.66)\end{array}$ & $\begin{array}{l}1.61 \\
(1.12,2.30)\end{array}$ & $\begin{array}{l}1.40 \\
(0.96,2.03)\end{array}$ & 1 & $3.3^{*} 10^{-6}$ \\
\hline $\begin{array}{l}\text { Diabetes } \\
\text { (unadjusted) }\end{array}$ & $\begin{array}{l}6.96 \\
(4.68,10.36)\end{array}$ & $\begin{array}{l}3.76 \\
(2.47,5.72)\end{array}$ & $\begin{array}{l}3.08 \\
(2.02,4.69)\end{array}$ & $\begin{array}{l}1.81 \\
(1.14,2.87)\end{array}$ & 1 & $5.13^{*} 10^{-38}$ \\
\hline $\begin{array}{l}\text { Diabetes } \\
\text { (adjusted) }\end{array}$ & $\begin{array}{l}3.14 \\
(2.00,4.94)\end{array}$ & $\begin{array}{l}2.36 \\
(1.5,3.7)\end{array}$ & $\begin{array}{l}2.04 \\
(1.32,3.15)\end{array}$ & $\begin{array}{l}1.55 \\
(0.97,2.46)\end{array}$ & 1 & $3.2^{*} 10^{-9}$ \\
\hline $\begin{array}{l}\text { Non CVD/diabetes } \\
\text { (unadjusted) }\end{array}$ & $\begin{array}{l}1.70 \\
(1.64,1.77)\end{array}$ & $\begin{array}{l}1.18 \\
(1.13,1.23)\end{array}$ & $\begin{array}{l}1.16 \\
(1.11,1.20)\end{array}$ & $\begin{array}{l}1.02 \\
(0.98,1.06)\end{array}$ & 1 & $7.78 * 10^{-247}$ \\
\hline $\begin{array}{l}\text { Non CVD/diabetes } \\
\text { (adjusted) }\end{array}$ & $\begin{array}{l}1.17 \\
(1.12,1.22)\end{array}$ & $\begin{array}{l}1.04 \\
(1.00,1.09)\end{array}$ & $\begin{array}{l}1.01 \\
(0.97,1.05)\end{array}$ & $\begin{array}{l}1.01 \\
(0.97,1.05)\end{array}$ & 1 & $1.3^{*} 10^{-19}$ \\
\hline
\end{tabular}

The association between fifths of GIT scores (in comparison to highest quintile) and cause of death was determined using unadjusted and after adjustment for age, sex, birth year, body mass index (BMI), residential socioeconomic status, education and country of origin

$H R$ Hazard ratio, $\mathrm{Cl}$ confidence interval, $C H D$ coronary heart disease, $C V D$ cardiovascular

the early years of the study, that affect the GIT account for the relationship. The strong reduction in the hazard ratios on multivariable adjustment, particularly for education, residential SES and origin (ie., model 4 adjustment), supports this explanation. Education is an increasingly non-discriminating variable in our 

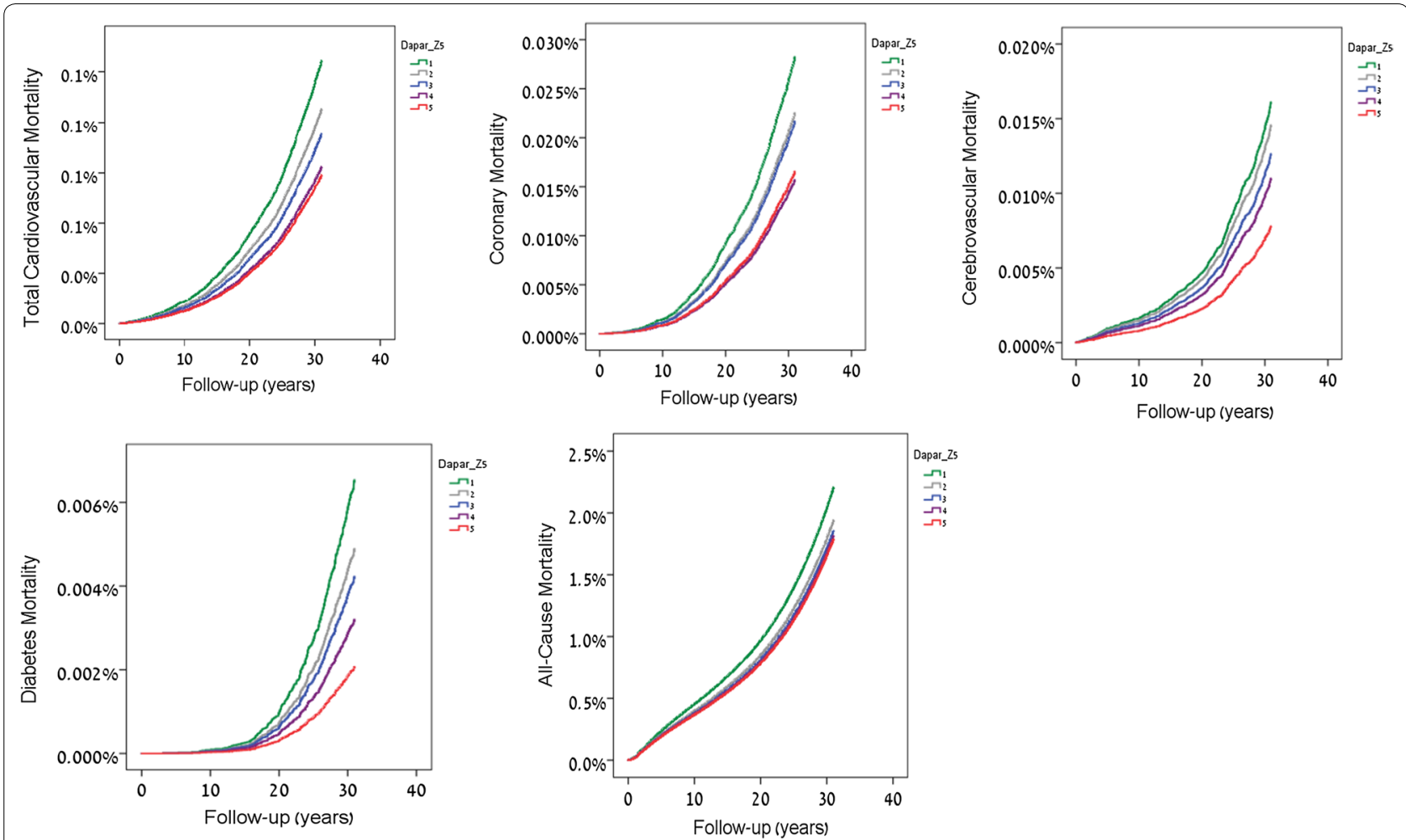

Fig. 2 Cox hazard ratios for mortality due to all cardiovascular disease, coronary heart disease, stroke, diabetes, and all-cause mortality for the highest GIT quintile in comparison to lower quintiles after multivariable adjustment for age, sex, birth year, BMI, residential SES, education and country of origin (Model 4)

data set as rapidly growing proportions over time have 12 years of education. Furthermore, we used an ecological measure of SES-based on locality of residence, which lacks refinement in cities. Therefore, residual confounding cannot be excluded as an explanation for the associations we report in multivariable-adjusted analyses. Alternatively, differences in GIT might be associated with different life-style behavioral patterns in childhood or specific intra-utero exposures (also referred to as fetal origin of adult disease [FOAD]) [39]. For example it has been suggested that low birth weight, a surrogate marker of poor nutrition and fetal growth, is associated with stroke, coronary heart disease, stroke and diabetes [40, 41]. Additionally, it could be that physical activity and diet in childhood could have affected intelligence scores and the subsequent risk for diabetes and CVD death in an independent manner. The observation of a shorter stature among adolescents with lower GIT may argue in favor of a common mechanism for these observation. For example, poor nutrition in early life and perhaps already in-utero may independently affect neurocognitive development (and thus lower GIT) [42-44], growth velocity (thus shorter stature) $[45,46]$ and may increase the risk for future development of the metabolic syndrome $[45,47]$ and its associated cardiometabolic risk. An additional possible explanation is that a higher GIT score leads to greater achievements, higher income, higher SES, a more healthy lifestyle, less exposure to a deleterious life-style, better access to healthcare and a better ability to prevent and manage disease [48-50]. Finally, it could be that the relationship observed suggests a common origin(s) or pathway for both cognitive function and dyglycemia. These might include, among others, mitochondrial (dys)function [51,52], the sortilin pathway [53], activation of the hypothalamic-pituitary-adrenal axis, inflammation, dysglycemia perse or brain and systemic insulin sensitivity [54-56]. Supporting the latter two explanations is the relatively strong relationship observed between cognitive function and diabetes-related mortality.

The study has several limitations. First, only a limited number of potential confounders were available for adjustment. Thus, information related to socio-demographic variables was restricted to country of origin, education and a residential-based index of SES in adolescence. Information related to individual measures of SES and to life-style factors such as diet, physical 


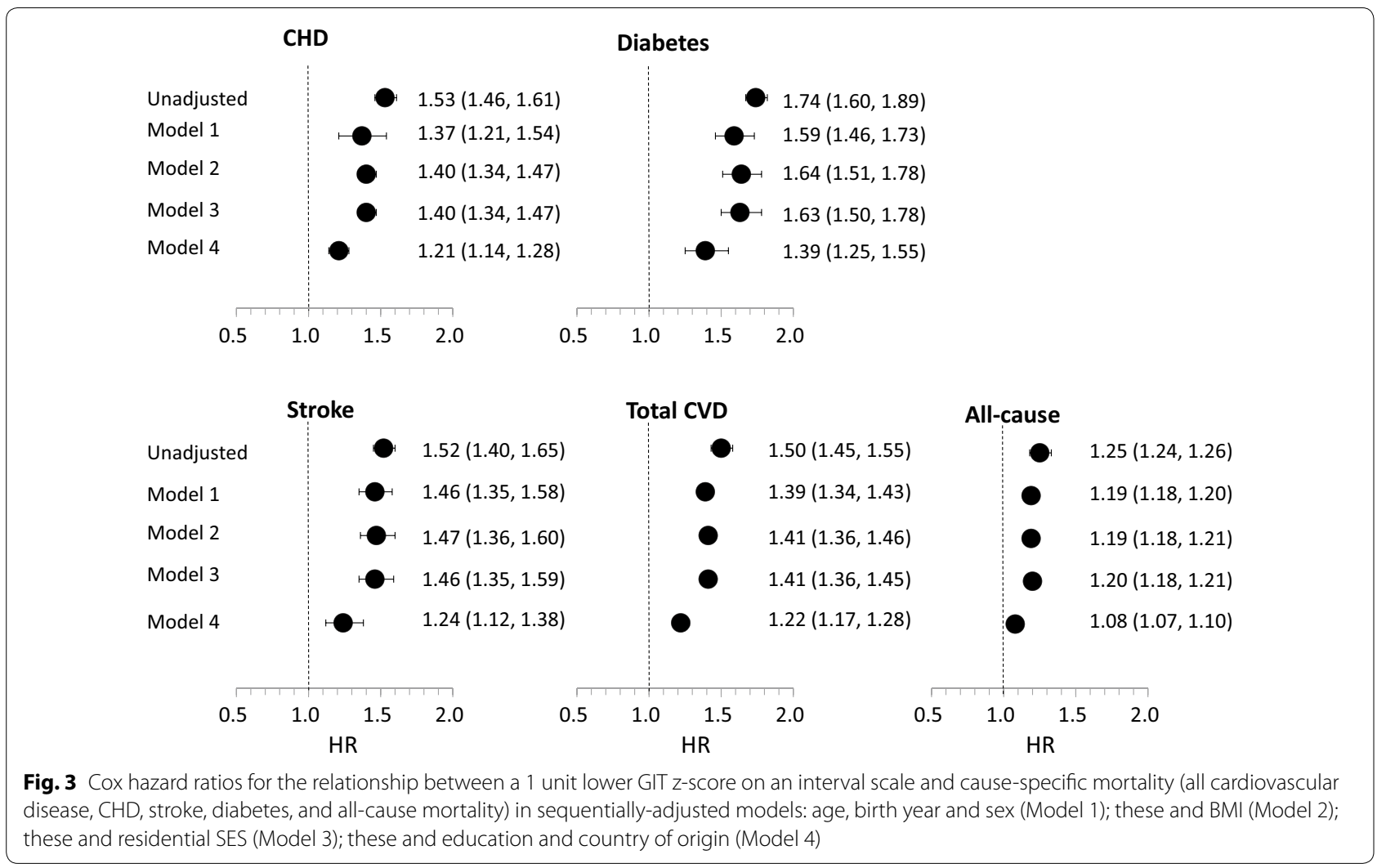

activity and smoking in adolescence (and adulthood) were not available, thus limiting our ability to assess an independent relationship (or an association mediated through these risk factors). Second, data regarding CVD mortality were not available from 1967 to 1981, however most cases of death during those years were attributable to service-based trauma, whereas the expected number of CVD or diabetes deaths was trivial [16]. The study has several strengths including the large sample size and consequently substantial statistical power, the inclusion of data with respect to both women and men, the largely unselected populationbased sampling and the ability to restrict the analysis to a healthy population.

\section{Conclusions}

To conclude, this analysis demonstrates an inverse relationship between cognitive function at the age of 17 and the risk for diabetes-related death as well as all-cause mortality and CVD-related death. The study's results emphasize the need for further research aimed at assessing an independent association of adolescent cognition with subsequent mortality as well as unravelling possible mechanistic routes that may explain the strong cognitive-diabetes relationship. On a clinical level, these results highlight the ability of cognitive tests to discriminate between individuals at higher and lower risk for CVD/diabetes death, thus possibly enabling targeted risk mitigation strategies and more intense follow-up for these high risk populations.

\section{Additional file}

Additional file 1. Additional analyses supporting the association between the general intelligence test score and cause-specific mortality.

\section{Abbreviations}

IQ: intelligence quotient; SES: socioeconomic status; GIT: general intelligence tests; CVD: cardiovascular; CHD: coronary heart disease; BMI: body mass index; IQR: inter-quartile range.

\section{Authors' contributions}

GT, TC-Y and JDK were responsible for study concept and design, statistical analysis and interpretation of the data, and drafting and redrafting of the manuscript. ED was responsible for statistical analysis. JDK, ED, NG and ZH were responsible for data acquisition. AT, HCG and AA contributed to critical revision of the manuscript. GT and JDK are the guarantors of this work and, as such, had full access to all the data in the study and take responsibility for the integrity of the data and the accuracy of the data analysis. All authors read and approved the final manuscript. 


\begin{abstract}
Author details
1 Department of Medicine, Sheba Medical Center, Tel Hashomer, Ramat Gan, Israel. ${ }^{2}$ The Israel Defense Forces Medical Corps, Ramat Gan, Israel. ${ }^{3}$ The Dr. Pinchas Bornstein Talpiot Medical Leadership Program, Sheba Medical Center, Ramat Gan, Israel. ${ }^{4}$ The Sackler School of Medicine, Tel Aviv University, Tel Aviv, Israel. ${ }^{5}$ Institute of Endocrinology, Sheba Medical Center, Tel Hashomer, Ramat Gan, Israel. ${ }^{6}$ Division of Endocrinology \& Metabolism, and Population Health Research Institute, McMaster University \& Hamilton Health Sciences, Hamilton, ON, Canada. ${ }^{7}$ The Division of Endocrinology, Diabetes and Hypertension, Brigham and Women's Hospital, Harvard Medical School, Boston, MA, USA. ${ }^{8}$ Israel Ministry of Health, Jerusalem, Israel. ${ }^{9}$ Hebrew University-Hadassah School of Public Health and Community Medicine, Ein Kerem, Jerusalem, Israel. ${ }^{10}$ Department of Military Medicine, Hebrew University, Jerusalem, Israel. ${ }^{11}$ Department of Epidemiology, Sackler School of Medicine, Herczeg institute on Aging, Tel-Aviv university, Tel-Aviv, Israel.
\end{abstract}

\section{Acknowledgements}

Prof. Jeremy Kark passed away during the preparation of this manuscript. This manuscript is dedicated to this memory with an unequivocal recognition in his contribution to cardiovascular and public health research in the past five decades.

\section{Competing interests}

The authors declare that they have no competing interests.

\section{Availability of data and materials}

The current database is not publically available due to individual privacy of the participants. However, it may be available from the corresponding author on reasonable request.

\section{Consent for publication}

Not applicable.

\section{Ethics approval and consent to participate}

The Israel Defense Forces Medical Corps Institutional Review Board approved this study and waived the need to an informed consent based on strict maintenance of participants'anonymity.

\section{Funding}

None.

\section{Publisher's Note}

Springer Nature remains neutral with regard to jurisdictional claims in published maps and institutional affiliations.

\section{Received: 10 October 2018 Accepted: 28 November 2018} Published online: 05 December 2018

\section{References}

1. Whalley LJ, Deary IJ. Longitudinal cohort study of childhood IQ and survival up to age 76. BMJ. 2001;322(7290):819.

2. Pavlik VN, de Moraes SA, Szklo M, Knopman DS, Mosley TH Jr, Hyman DJ. Relation between cognitive function and mortality in middle-aged adults: the atherosclerosis risk in communities study. Am J Epidemiol. 2003; 157(4):327-34.

3. Deary IJ, Der G. Reaction time explains IQ's association with death. Psychol Sci. 2005;16(1):64-9.

4. Cukic I, Brett CE, Calvin CM, Batty GD, Deary IJ. Childhood IQ and surviva to 79 : follow-up of $94 \%$ of the Scottish mental survey 1947. Intelligence. 2017:63:45-50.

5. Calvin CM, Deary IJ, Fenton C, et al. Intelligence in youth and allcause-mortality: systematic review with meta-analysis. Int J Epidemiol. 2011;40(3):626-44.

6. Calvin CM, Batty GD, Der G, et al. Childhood intelligence in relation to major causes of death in 68 year follow-up: prospective population study. BMJ. 2017;357:j2708.
7. Batty GD, Wennerstad KM, Smith GD, et al. IQ in early adulthood and mortality by middle age: cohort study of 1 million Swedish men. Epidemiology. 2009;20(1):100-9.

8. Starr JM, Taylor MD, Hart CL, et al. Childhood mental ability and blood pressure at midlife: linking the Scottish Mental Survey 1932 and the Midspan studies. J Hypertens. 2004;22(5):893-7.

9. Hart CL, Taylor MD, Smith GD, et al. Childhood IO and cardiovascular disease in adulthood: prospective observational study linking the Scottish Mental Survey 1932 and the Midspan studies. Soc Sci Med. 2004;59(10):2131-8

10. Hart CL, Taylor MD, Davey Smith G, et al. Childhood IQ, social class, deprivation, and their relationships with mortality and morbidity risk in later life: prospective observational study linking the Scottish Mental Survey 1932 and the Midspan studies. Psychosom Med. 2003;65(5):877-83.

11. Batty GD, Deary IJ, Schoon I, Gale CR. Childhood mental ability in relation to cause-specific accidents in adulthood: the 1970 British Cohort Study. QJM. 2007;100(7):405-14.

12. Schmidt M, Johannesdottir SA, Lemeshow S, et al. Cognitive test scores in young men and subsequent risk of type 2 diabetes, cardiovascular morbidity, and death. Epidemiology. 2013;24(5):632-6.

13. Yano Y, Bakris GL, Inokuchi T, et al. Association of cognitive dysfunction with cardiovascular disease events in elderly hypertensive patients. J Hypertens. 2014;32(2):423-31.

14. O'Donnell M, Teo K, Gao P, et al. Cognitive impairment and risk of cardiovascular events and mortality. Eur Heart J. 2012;33(14):1777-86.

15. Twig G, Gluzman I, Tirosh A, et al. Cognitive function and the risk for diabetes among young men. Diabetes Care. 2014;37(11):2982-8.

16. Twig $G$, Tirosh A, Leiba A, et al. BMl at age 17 years and diabetes mortality in midlife: a nationwide cohort of 2.3 million adolescents. Diabetes Care. 2016;39(11):1996

17. Twig G, Yaniv G, Levine $H$, et al. Body-mass index in 2.3 million adolescents and cardiovascular death in adulthood. N Engl J Med. 2016;374(25):2430-40.

18. Davidson M, Reichenberg A, Rabinowitz J, Weiser M, Kaplan Z, Mark M. Behavioral and intellectual markers for schizophrenia in apparently healthy male adolescents. Am J Psychiatry. 1999;156(9):1328-35.

19. Reichenberg A, Weiser M, Rapp MA, et al. Premorbid intra-individual variability in intellectual performance and risk for schizophrenia: a populationbased study. Schizophr Res. 2006;85(1-3):49-57.

20. Lezak M. Neuropshychological assessment. Oxford: Oxford Press; 2004.

21. Gal R. The selection, classification and placement process, in a portrait of the Israeli soldier. Westport: Greenwood Pres; 1986.

22. Twig G, Reichman B, Afek A, et al. Severe obesity and cardio-metabolic comorbidities: a nationwide study of 2.8 million adolescents. Int J Obesity. 2018. https://doi.org/10.1038/s41366-018-0213-z.

23. Furer A, Afek A, Orr O, et al. Sex-specific associations between adolescent categories of BMI with cardiovascular and non-cardiovascular mortality in midlife. Cardiovasc Diabetol. 2018;17(1):80.

24. Twig G, Geva N, Levine H, et al. Body mass index and infectious disease mortality in midlife in a cohort of 2.3 million adolescents. Int J Obesity. 2018:42(4):801-7.

25. Statistics ICBO. Characterization and classification of local authorities by the socio-economic level of the population. Jerusalem: Israel Central Bureau of Statistics; 2006.

26. Twig G, Afek A, Shamiss A, et al. Adolescence BMI and trends in adulthood mortality: a study of 2.16 million adolescents. J Clin Endocrinol Metab. 2014:99(6):2095-103.

27. Twig G, Ben-Ami Shor D, Furer A, et al. Adolescent body mass index and cardiovascular disease-specific mortality by midlife. J Clin Endocrinol Metab. 2017;102(8):3011-20.

28. Jason P, Fine RJG. A proportional hazards model for the subdistribution of a competing risk. J Am Stat Assoc. 1999;1999(94):496-509.

29. Twig G, Geva N, Levine $H$, et al. Body mass index and infectious disease mortality in midlife in a cohort of 2.3 million adolescents. Int J Obesity. 2017:42:801-7.

30. Twig G, Vivante A, Bader T, et al. Body mass index and kidney diseaserelated mortality in midlife: a nationwide cohort of 2.3 million adolescents. Obesity. 2018;26(4):776-81. 
31. de Galan BE, Zoungas S, Chalmers J, et al. Cognitive function and risks of cardiovascular disease and hypoglycaemia in patients with type 2 diabetes: the Action in Diabetes and Vascular Disease Preterax and Diamicron Modified Release Controlled Evaluation (ADVANCE) trial. Diabetologia. 2009;52(11):2328-36.

32. Batty GD, Deary IJ, Zaninotto P. Association of cognitive function with cause-specific mortality in middle and older age: follow-up of participants in the english longitudinal study of ageing. Am J Epidemiol. 2016:183(3):183-90.

33. Cukierman-Yaffe T, Kasher-Meron M, Fruchter E, et al. Cognitive performance at late adolescence and the risk for impaired fasting glucose among young adults. J Clin Endocrinol Metab. 2015;100(12):4409-16.

34. Galobardes B, Smith GD, Lynch JW. Systematic review of the influence of childhood socioeconomic circumstances on risk for cardiovascular disease in adulthood. Ann Epidemiol. 2006;16(2):91-104.

35. Galobardes B, Lynch JW, Smith GD. Is the association between childhood socioeconomic circumstances and cause-specific mortality established? Update of a systematic review. J Epidemiol Community Health. 2008;62(5):387-90.

36. Galobardes B, Lynch JW, Davey Smith G. Childhood socioeconomic circumstances and cause-specific mortality in adulthood: systematic review and interpretation. Epidemiol Rev. 2004;26:7-21.

37. Feinstein $L$, Bynner J. The importance of cognitive development in middle childhood for adulthood socioeconomic status, mental health, and problem behavior. Child Dev. 2004;75(5):1329-39.

38. Jefferis BJ, Power C, Graham H, Manor O. Effects of childhood socioeconomic circumstances on persistent smoking. Am J Public Health. 2004;94(2):279-85.

39. Calkins K, Devaskar SU. Fetal origins of adult disease. Curr Prob Pediatric Adolesc Health Care. 2011;41(6):158-76.

40. Barker DJ, Osmond C. Infant mortality, childhood nutrition, and ischaemic heart disease in England and Wales. Lancet. 1986;1(8489):1077-81.

41. Boyko EJ. Proportion of type 2 diabetes cases resulting from impaired fetal growth. Diabetes Care. 2000;23(9):1260-4.

42. Nyaradi A, Li J, Hickling S, Foster J, Oddy WH. The role of nutrition in children's neurocognitive development, from pregnancy through childhood. Front Hum Neurosci. 2013;7:97.

43. Grantham-McGregor S, Cheung YB, Cueto S, et al. Developmental potential in the first 5 years for children in developing countries. Lancet. 2007;369(9555):60-70

44. Alaimo K, Olson CM, Frongillo EA Jr. Food insufficiency and American school-aged children's cognitive, academic, and psychosocial development. Pediatrics. 2001;108(1):44-53.
45. DeBoer MD, Lima AA, Oria RB, et al. Early childhood growth failure and the developmental origins of adult disease: do enteric infections and malnutrition increase risk for the metabolic syndrome? Nutr Rev. 2012;70(11):642-53.

46. Schwinger C, Fadnes LT, Shrestha SK, et al. Predicting undernutrition at age 2 years with early attained weight and length compared with weight and length velocity. J Pediatr. 2017;182(127-32):e1.

47. Lucove JC, Kaufman JS, James SA. Association between adult and childhood socioeconomic status and prevalence of the metabolic syndrome in African Americans: the pitt county study. Am J Public Health. 2007;97(2):234-6.

48. Gottfredson LS. Intelligence: is it the epidemiologists' elusive "fundamental cause" of social class inequalities in health? J Pers Soc Psychol. 2004;86(1):174-99.

49. Deary IJ, Gale CR, Stewart MC, et al. Intelligence and persisting with medication for two years: analysis in a randomised controlled trial. Intelligence. 2009;37(6):607-12.

50. Patel R, Lawlor DA, Ebrahim S, British Women's H, Health Study C. Socioeconomic position and the use of preventive health care in older British women: a cross-sectional study using data from the British Women's Heart and Health Study cohort. Fam Pract. 2007;24(1):7-10.

51. Befroy DE, Petersen KF, Dufour S, et al. Impaired mitochondrial substrate oxidation in muscle of insulin-resistant offspring of type 2 diabetic patients. Diabetes. 2007;56(5):1376-81.

52. Petersen KF, Befroy D, Dufour S, et al. Mitochondrial dysfunction in the elderly: possible role in insulin resistance. Science. 2003:300(5622):1140-2.

53. Lane RF, Raines SM, Steele JW, et al. Diabetes-associated SorCS1 regulates Alzheimer's amyloid-beta metabolism: evidence for involvement of SorL1 and the retromer complex. J Neurosci. 2010;30(39):13110-5.

54. Craft S, Cholerton B, Baker LD. Insulin and Alzheimer's disease: untangling the web. J Alzheimers Dis. 2013;33(Suppl 1):S263-75.

55. Geerlings MI, Brickman AM, Schupf N, et al. Depressive symptoms, antidepressant use, and brain volumes on MRI in a population-based cohort of old persons without dementia. J Alzheimers Dis. 2012;30(1):75-82.

56. Schioth HB, Craft S, Brooks SJ, Frey WH 2nd, Benedict C. Brain insulin signaling and Alzheimer's disease: current evidence and future directions. Mol Neurobiol. 2012:46(1):4-10.
Ready to submit your research? Choose BMC and benefit from:

- fast, convenient online submission

- thorough peer review by experienced researchers in your field

- rapid publication on acceptance

- support for research data, including large and complex data types

- gold Open Access which fosters wider collaboration and increased citations

- maximum visibility for your research: over $100 \mathrm{M}$ website views per year

At $\mathrm{BMC}$, research is always in progress.

Learn more biomedcentral.com/submissions 